\title{
Solutions for the size \& concentration measurement of aerosols from combustion
}

\author{
Lucia Bustin ${ }^{1, *}$, Florian Dahlkötter ${ }^{1}$, Carsten Kykal $^{1}$, Torsten Tritscher $^{1}$, and Oliver F. \\ Bischof $^{1}$ \\ ${ }^{1}$ TSI GmbH, Neuköllner Str. 4, 52068 Aachen, Germany
}

\begin{abstract}
Currently the main pollution comes from the anthropogenic sources related to residential heating and combustion. Most of the emitted particles from this sources are in the mode below $1 \mu \mathrm{m}$. Therefore, only by using methods based on the electric mobility separation and size enhancement we can measure the size and concentration of this particles from nano to ultrafine sizes. This contribution describes the most recent methods how to study particle size and concentration of the particles coming from combustion sources.
\end{abstract}

\section{Introduction}

Many aerosol sources of interest, like combustion, cigarette smoke, emission form biomass burning and any other anthropogenic production consist of particles in the size range from few nanometers to $1 \mu \mathrm{m}$ [1]. Current mass limits of PM 2.5 and PM 10 demand measurement of particle size up to $2.5 \mu \mathrm{m}$ or $10 \mu \mathrm{m}$, which do not represent particles coming from anthropogenic sources mainly from combustion. A key parameter for the combustion source characterization is the number size distribution measurement from few nano meters up to $1 \mu \mathrm{m}$ by either high resolution Scanning Mobility Particle Sizer ${ }^{\mathrm{TM}}$ (SMPSTM, TSI model 3938) spectrometer or with fast sizer Engine Exhaust Particle Sizer (EEPSTM, TSI model 3090) working at $0.1 \mathrm{~Hz}$ sampling rate. The size range of spectrometers can be extended by an Optical Particle Sizer (OPS, TSI model 3330) that covers larger sizes from $300 \mathrm{~nm}$ to $10 \mu \mathrm{m}$. Or Aerodynamic Particle Sizer (APS ${ }^{\circ}$, TSI model 3321).

\section{Methods}

Electrical mobility technique has increased use in the in-situ near real-time sizing of aerosol-based processes like diffusion flame synthesis, spray pyrolysis, thermal plasma, and combustion processes etc. With the commercialization of nanotechnology, and increasing interest in exposure monitoring and ambient air monitoring interests, the demand on precise sizing of nano particles, ultrafine particles and micro particles has grown. This contribution provides a brief overview of the electrical mobility technology as integrated in TSI

\footnotetext{
*Corresponding author: lucia.bustin@tsi.com
} 
SMPS $^{\mathrm{TM}}$ and EEPS ${ }^{\mathrm{TM}}$ spectrometers followed by the use of electrostatic classification $[2,3]$ as the only method for on-line measurements of size and number concentration of nano and ultrafine particles that are mainly present in the combustion sources.

TSI spectrometers consist of a sample preconditioner, a bipolar charger, a nanoparticle size classifier and a particle detector. The charger (also referred as neutralizer) establishes charge equilibrium on the particles. This defined charge condition is necessary for the size classification using electrical mobility. Particles are size classified in a Differential Mobility Analyzer (DMA). The electric field inside DMA separates the particles according to their electrical mobility, which is inversely related to the particle size. The electrical mobility of these selected particles is a function of flow rates, geometric parameters and the voltage of the center electrode. The size selected particle stream exiting the DMA is counted either by a Condensation Particle Counter (CPC) in SMPS or by electrometers placed around the center rod to collect the signal from electrons repealed from the center electrode in EEPS. This technique has a considerable reputation for its reliability and the fact that it is based on basic physical principles.

Typical experimental arrangements to study particle number-sized distribution (PN) of aerosols coming from combustion is depicted in Figure 1. The exhaust emissions are diluted and recently sampled by TSI spectrometers.

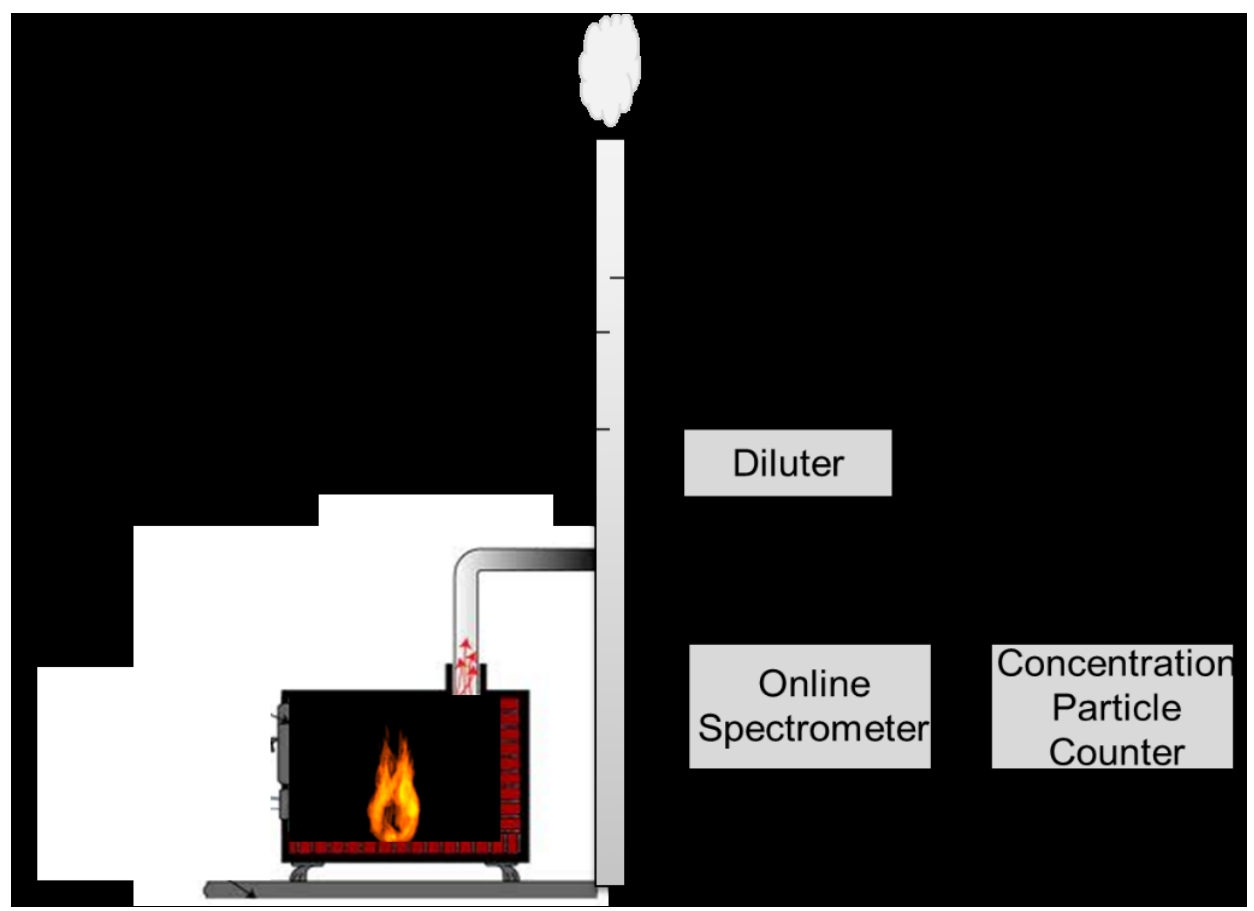

Fig. 1. Most common experimental set up to measure particle number and particle mass coming from combustion source.

\section{Results and Discussion}

The emission during combustion of wood in a small batch reactor were investigated by one of TSI spectrometers sizing from $10 \mathrm{~nm}$ up to $10 \mu \mathrm{m}$ to measure number size distribution. However, we pay attention only to results below $1 \mu \mathrm{m}$. 
The different phases of wood combustion are distinguishable by the particle number size distribution. The Figure 2 shows the differences in particle concentration present in nucleation mode so called Aitken mode (up to $40 \mathrm{~nm}$ ) [4, 5]. The increase of particles concentration in nucleation mode is visible by adding the compressed wood. The nucleation mode is created by particles freshly emitted from the combustion source. It is shown that the combustion conditions (e.g. load, air supply, temperature...) strongly influence the particle size and concentration.

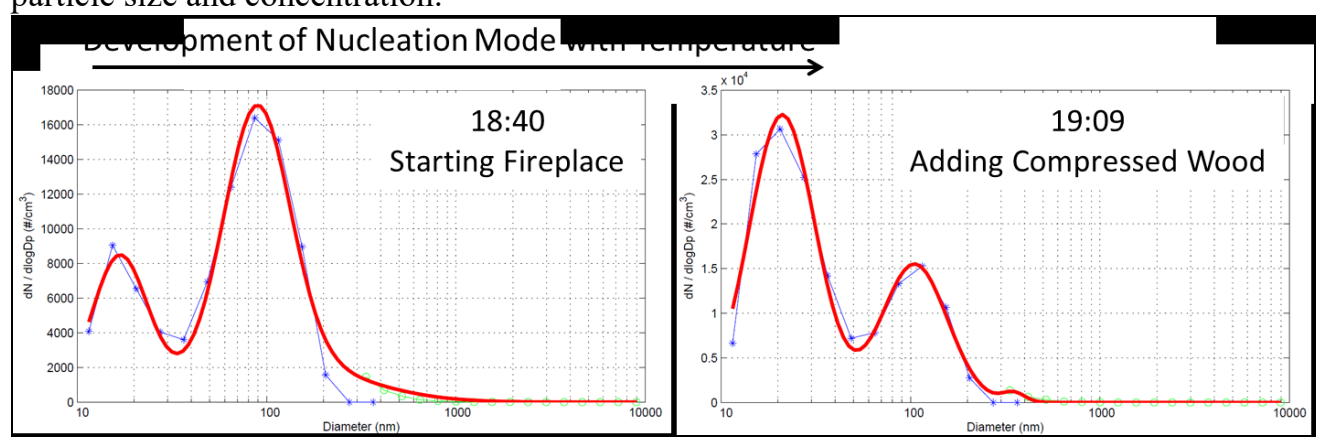

Fig. 2. Development of nucleation mode by adding compressed wood into combustion process.

Besides, the importance of the particle number size distribution determination is its relation the NOx emission. These days' scientists focus on NOx reduction. There are strategies to reduce NOx impact by using PN / PM control. As PM depends on combustion mode and NOx control strategy [6].

\section{References}

1. M.L. Souza, A.G. Allen, A.A Cardoso, Understanding aerosol formation mechanisms in a subtropical atmosphere impacted by biomass burning and agroindustry. Atmospheric Research, Vol. 183, 1, p.94-103 (2017)

2. E.O. Knutson, K.T Whitby, Aerosol Classification by Electric Mobility: Apparatus Theory and Applications, J. Aerosol Sci. Vol 6. p. 443-451, (1975)

3. S.C. Wang, R.C Flagan., Scanning Electrical Mobility Spectrometer. Aerosol Science and Technology, Vol. 13, 2 (1990)

4. J.H. Seinfeld, S.N Pandis, Atmospheric chemistry and Physics. John Willey and Sons, NewYork. (2006)

5. W.C Hinds, Aerosol Technology: properties, behavior and measurements of airborne particles. $2^{\text {nd }}$ ed., A Wiley Interscience publication. ISBN 0-471-19410-7(1999)

6. 2016 Annual Merit Review, Vehicle Technologies Office Results Report December 2016 Prepared by Allegheny Science \& Technology for the U.S. Department of Energy, Vehicle Technologies Office. ORNL, SAE 2016-01-0934, DOE AMR(2016) 